\title{
Status of lipid and lipoprotein in female breast cancer patients at initial diagnosis and during chemotherapy
}

\author{
Xin Li ${ }^{\dagger}$, Zi-li Liu ${ }^{\dagger}$, Yu-tuan Wu${ }^{\dagger}$, He Wu${ }^{\dagger}$, Wei Dai, Bilal Arshad, Zhou Xu, Hao Li, Kai-nan Wu and Ling-quan Kong ${ }^{*}$
}

\begin{abstract}
Background: The lipid profile status among breast cancer patients at initial diagnosis and during chemotherapy remain controversial. The aim of this study is to study the status of lipid and lipoprotein in female breast cancer patients at initial diagnosis and during chemotherapy.

Methods: We conducted a retrospective cohort study of the status of the lipid and lipoprotein in 1054 primarily diagnosed breast cancer patients and 2483 normal controls with age stratification, from July 2015 to October 2016. At the same time, the status of lipid and lipoprotein were also analyzed among 394 breast cancer patients before and after adjuvant chemotherapy.

Results: The incidence of dyslipidemia was significantly lower in breast cancer group(42.98\%) compared to normal group $(58.28 \%)(P<0.001)$. The levels of total cholesterol $(T C)$, triglycerides $(T G), H D L$ cholesterol $(H D L-C)$, LDL cholesterol (LDL-C) among breast cancer group were significantly lower compared to normal control group $(P<0.05)$. With age stratification, the levels of TC and LDL-C in breast cancer group were still significantly lower than those in control group $(P<0.001)$. And the levels of $T C, T G, L D L-C$, apolipoprotein $B$ were significantly higher among post chemotherapeutic patients compared to prechemotherapeutic patients, however HDL-C and Apo-A1 levels were contrary.

Conclusions: Breast cancer patients have lower incidence of dyslipidemia compared to normal populations. However, the situation of dyslipidemia may become worsened after chemotherapy. Therefore, lipid monitoring and dyslipidemia prevention and treatment should be conducted for breast cancer patients at initial diagnosis and during chemotherapy.
\end{abstract}

Keywords: Breast cancer, Dyslipidemia, Adjuvant chemotherapy

\section{Background}

Breast cancer is the most general diagnosed cancer and the second leading cause of cancer-related death among women worldwide [1]. The female breast cancer mortality is down to $36 \%$ from peak rates due to early diagnosis and treatment [2]. However, it is still crucial to investigate the relative hazardous factors and methods to improve prognosis.

An unbalanced lipid profile with high total cholesterol (TC), low-density lipoprotein-cholesterol (LDL-C),

\footnotetext{
*Correspondence: huihuikp@163.com

${ }^{\dagger}$ Equal contributors

Department of Endocrine and Breast Surgery, The First Affiliated Hospital of Chongqing Medical University, Chongqing 400016, China
}

triglycerides (TG), and low high-density lipoproteincholesterol (HDL-C), apolipoprotein A1(Apo-A1), apolipoprotein $B$ (Apo-B) is an established risk factor of cardiovascular diseases [3, 4]. LDL-C has been successfully treated by lipid-lowering therapies. Apolipoproteins are crucial for the development of HDL and LDL lipoprotein complex. Moreover, Apo-B is considered as a better indicator of cardiovascular disease (CVD) compared to LDL-C [5]. Apo-A1 binding protein accelerates cholesterol efflux from endothelial cells and regulates angiogenesis [6]. Plasma lipids and lipoproteins are influenced by environmental factors, including weight and diet, and are closely associated with breast cancer risk factors which suggest the role of lipids in causing breast

(C) The Author(s). 2018 Open Access This article is distributed under the terms of the Creative Commons Attribution 4.0 International License (http://creativecommons.org/licenses/by/4.0/), which permits unrestricted use, distribution, and 
cancer. A study suggested that higher mammographic density considered to be a strong risk factor of breast cancer [7], which is associated with increased HDL-C levels and decreased LDL-C levels [8]. Furthermore, HDL-C level is associated with several other breast cancer risk factors [9]. Several studies have reported the association between lipids and breast cancer. However, the results are controversial. Some prospective clinical studies reported that high levels of TC and HDL-C may increase breast cancer incidence [9-11]. However, others have suggested that low TC and HDL-C levels could increase breast cancer risk [12, 13]. Few researches have studied the status of lipid in breast cancer patients before and after chemotherapy. Derya H B et al. reported that adjuvant chemotherapy may contribute to an increased risk for metabolic syndrome in breast cancer patients and these changes are more profound in premenopausal patients [14]. The aim of this study is to investigate the status of serum lipids and lipoproteins in breast cancer patients and normal controls and their changes during chemotherapy.

\section{Methods}

\section{Subjects}

The clinical data of blood lipid status of 1054 primarily diagnosed breast cancer patients and 2483 normal women (as controls) were collected from the electronic medical records of Breast Cancer Center and Chongqing Physical Examination Center of the First Affiliated Hospital of Chongqing Medical University, from July 2015 to October 2016. The data were comparatively analyzed with age stratification. Also the blood lipid status of 394 breast cancer patients were comparatively analyzed before and after chemotherapy. Key exclusion criteria included the patients with history of other malignancy and tumor recurrence and with no pathological reports.

\section{Evaluate parameters}

This study compares the status of lipids among breast cancer patients and normal people. The status of lipid and apolipoprotein of 394 breast cancer patients were evaluated before and after chemotherapy. The biochemical parameters related to dyslipidemia TC, TG, HDL, LDL, Apo A-1, Apo-B were categorized using cut-off values as follows: TC with $5.20 \mathrm{mmol} / \mathrm{L}$, TG $1.7 \mathrm{mml} / \mathrm{L}$, HDL-C $0.9 \mathrm{mmol} / \mathrm{L}$, LDL-C $3.1 \mathrm{mmol} / \mathrm{L}$. Dyslipidemia was considered when TC $>5.2 \mathrm{mmol} / \mathrm{L}$ or TG $>1.7 \mathrm{mmol} / \mathrm{L}$ or $\mathrm{LDL}-\mathrm{C}>3.1 \mathrm{mmol} / \mathrm{L}$ or HDL-C $<0.9 \mathrm{mmol} / \mathrm{L}$.

\section{Statistical analysis}

The data were analyzed using the Statistical Pakage for Social Sciences (SPSS) software version 22.0. Mean (x) and standard deviation (SD) were evaluated using student $\mathrm{t}$-test for the comparison between control and patient groups. $P<0.05$ was considered statistically significant. The incidence of dyslipidemia among both groups was compared using Chi-square test. The mean values of lipids among both groups were compared using independent sample $\mathrm{T}$ test. Finally, the status of blood lipids and apolipoproteins in breast cancer patients before and after chemotherapy were compared using paired-sample $\mathrm{T}$ test.

\section{Results}

No significant difference was observed in the mean age of breast cancer group $(49.93 \pm 10.44$ years $)$ and control group (50.16 \pm 12.07 years). In our study, We observed the prevalence of preobese or obesity $(\mathrm{BMI} \geq 25)$ was $27.61 \%$ in breast cancer patients and $22.43 \%$ in control population, respectively. Baseline characteristics of breast cancer patients and control population are shown in Table 1.

The incidence of dyslipidemia was significantly lower in breast cancer group compared to control

Table 1 Baseline characteristics of the study population

\begin{tabular}{llll}
\hline Characteristics & Breast cancer $(n=1054)$ & Control group $(n=2483)$ & $P$-value \\
\hline Age, years(Mean \pm SD) & $49.93 \pm 10.43$ & $50.16 \pm 12.07$ & 0.569 \\
Body mass index $(\mathrm{BMI}), \mathrm{kg} / \mathrm{m}$ 2(Mean $\pm \mathrm{SD})$ & $23.44 \pm 3.16$ & $22.86 \pm 3.09$ & $<0.001$ \\
Underweight $(\mathrm{BMI}<18.5)(\mathrm{n}, \%)$ & $53(5.03)$ & $124(4.99)$ & 0.004 \\
Normal $(18.5 \leq \mathrm{BMI} \leq 25)(\mathrm{n}, \%)$ & $710(67.36)$ & $1802(72.57)$ \\
Preobese $(25 \leq \mathrm{BMI} \leq 30)(\mathrm{n}, \%)$ & $253(24.00)$ & $503(20.26)$ \\
Obesity $(\mathrm{BMI} \geq 30)(\mathrm{n}, \%)$ & $38(3.61)$ & $54(2.17)$ \\
Stage $(n, \%)$ & & - & \\
I & $311(29.51)$ & - & - \\
II & $456(43.26)$ & - & - \\
III & $214(20.30)$ & - & - \\
IV & $4(0.38)$ & - & - \\
Missing & $69(6.54)$ & - \\
\hline
\end{tabular}




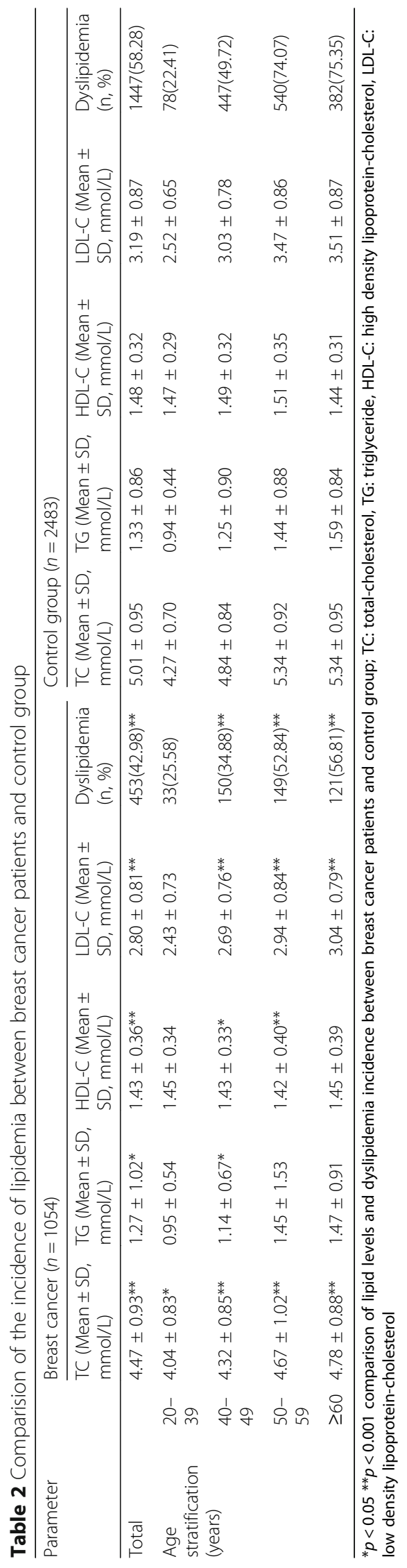


Table 3 The baseline characteristics of the patients received chemotherapy

\begin{tabular}{ll}
\hline Characteristics & Value \\
\hline Age, years, mean \pm SD & $48.31 \pm 8.80$ \\
menopausal status at diagnosis & \\
premenopausal $(n, \%)$ & $239(60.66)$ \\
post menopausal $(n, \%)$ & $155(39.34)$ \\
Weight & \\
prechemotherapy, mean \pm SD (KG) & $56.70 \pm 7.64$ \\
post chemotherapy, mean \pm SD(KG) & $58.06 \pm 7.74$ \\
Chemotherapy regimens & \\
TAC ( $n, \%)$ & $251(63.71)$ \\
AC-T $(n, \%)$ & $134(34.01)$ \\
CEF $(n, \%)$ & $9(2.28)$ \\
\hline
\end{tabular}

group $(P<0.001)$. The levels of TC and LDL-C in breast cancer group were significantly lower than those in control group $(P<0.001)$. With age stratification, the levels of TC and LDL-C in breast cancer group were still significantly lower than those in control group $(P<0.001)$. Significant statistical difference was observed in the TG level of breast cancer group compared to normal group $(P<0.05)$; While with age stratification, decreased TG level in breast cancer group was found only in 40-49 years group $(P<0.05)$. There was a significant statistical difference in HDL-C level among breast cancer group compared to control group $(P<0.001)$, respectively; While with age stratification, the HDL-C level was significantly higher in normal group in 40-59 years group $(P<0.05)$. The comparison of lipid profiles in breast cancer group and control group are shown in Table 2 .

The basic situation of patients received chemotherapy were shown in Table 3, and it recorded the weight changes before and after chemotherapy. TAC chemotherapy regimen (docetaxel, doxorubicin, cyclophosphamide), cycled every 21 days for 6 cycles. AC-T chemotherapy regimen (doxorubicin and cyclophosphamide, cycled every 21 days for 4 cycles. Followed by docetaxel, cycled every 21 days for 4 cycles). CEF chemotherapy regimen(5- fluorouracil Epirubicin and cyclophosphamide),cycled every 21 days for 6 cycles.

Comparison of lipid profiles in 394 breast cancer patients before and after chemotherapy is shown in Table 4. Regarding to various lipid parameters, the differences in lipid levels of TC, TG, LDL-C, Apo-B (increase in blood levels), HDL-C and Apo-A1(decrease in blood levels) were statistically significant before 1 st chemotherapeutic cycle compared to the last cycle $(P<0.001)$. The levels of TC, TG, LDL-C, Apo-Bin among primarily diagnosed breast cancer patients before chemotherapy were $4.47 \pm 0.91,1.31 \pm 1.20,2.78 \pm 0.80$ and $0.85 \pm 0.23$, however the levels after chemotherapy, increased to $4.80 \pm 0.88,1.77 \pm 1.21,3.18 \pm 0.81$ and $0.97 \pm 0.24$, respectively $(P<0.001)$. The prechemotherapeutic levels of HDL-C and Apo-A1 significantly decreased after chemotherapy $(P<0.001)$. The changes in lipid level among premenopausal and postmenopausal women undergoing chemotherapy were similar to the normal patients.

\section{Discussion}

In this study, we demonstrate that the incidence of dyslipidemia in breast cancer patients (42.98\%) was significantly lower than that in control group $(58.28 \%, P<0.001)$, and the total serum levels of cholesterol, triglycerides, HDL-C and LDL-C are significantly lower in breast cancer patients than those in normal controls in southwest of China. The cholesterol increased significantly during chemotherapy, except for the decrease in HDL-C.

A study results refers to that the thyroxine(T4) level in initially diagnosed breast cancer patients were significantly higher than those in benign breast diseases patients. And during chemotherapy, the T4, free triiodothyronine (FT3), and free thyroxine (FT4), were significantly lower than in initially diagnosed breast cancer patients [15]. It is well known that increased thyroxin

Table 4 Comparision of the status of lipidemia between breast cancer patients with pre and post chemotherapy

\begin{tabular}{lllll}
\hline Parameter & \multicolumn{2}{l}{ Pre-chemotherapy group $(n=394)$} & & \multicolumn{2}{l}{ Post-chemotherapy group $(n=394)$} \\
\cline { 2 - 5 } & Mean \pm SD $(\mathrm{mmol} / \mathrm{L})$ & Abnormal $(\mathrm{n}, \%)$ & $4.80 \pm 0.88$ & $119(30.20)$ \\
\hline TC & $4.47 \pm 0.91^{* *}$ & & Mean \pm SD $(\mathrm{mmol} / \mathrm{L})$ & $160(40.61)$ \\
TG & $1.31 \pm 1.20^{* *}$ & $72(18.27)^{* *}$ & $1.77 \pm 1.21$ & $42(10.66)$ \\
HDL-C & $1.43 \pm 0.36^{* *}$ & $20(5.08)^{*}$ & $1.28 \pm 0.35$ & $203(51.52)$ \\
LDL-C & $2.78 \pm 0.80^{* *}$ & $135(34.26)^{* *}$ & $3.15 \pm 0.81$ & $35(8.88)$ \\
Apo-A1 & $1.48 \pm 0.25^{* *}$ & $10(2.54)^{* *}$ & $1.39 \pm 0.24$ & $20(5.08)$ \\
Apo-B & $0.85 \pm 0.23^{* *}$ & $11(2.79)$ & $0.97 \pm 0.24$ & $306(68.61)$ \\
Dyslipidemia & - & $201(45.07) * *$ & - &
\end{tabular}

${ }^{*} p<0.05 * * p<0.001$ comparision of the status of lipidemia between pre and post chemotherapy among breast cancer patients; TC: total-cholesterol,

TG: triglyceride, HDL-C: high density lipoprotein-cholesterol, LDL-C: low density lipoprotein-cholesterol, Apo-A1: apolipoprotein-A1, Apo-B: apolipoprotein-B 
level may decrease cholesterol level [16]. Compared with normal population, the breast cancer patients were in higher cholesterol levels, and the increased cholesterol level among chemotherapeutic patients may be partly related with the increased thyroxin level during chemotherapy which had been found by our previous studies [15, 17].

Currently, some studies have investigated the association between lipids and breast cancer. A large prospective studies in Korea implicated that higher cholesterol increased the breast cancer risk [18]. However, the data from other studies generally do not support the association between cholesterol and breast cancer risk [19-21]. A recent meta-analysis about association of lipid profile levels to breast cancer females implicated no significant differences in the levels of total cholesterol, low density lipoprotein cholesterol between cases and controls [22]. These data support an inverse association between cholesterol levels, which has been previously reported [13, 23-25]. Fiorenza AM and his colleague got the similar results to ours, cancer patients had lower mean total cholesterol, LDL-C, and HDL-C than noncancer subjects. Patients with metastatic disease had lower total cholesterol and LDL-C than patients without metastasis [26]. Knapp et al. observed low LDL-C and HDL-C in patients with advance breast cancer [27]. An earlier observational results clearly indicated that hypocholesterolemia among cancer patients is due to disease progression [28]. Low LDL-C in malignancy might be explained by an increased demand of cholesterol from neoplastic cells, resulting in increased LDL removal through the enhancement of LDL receptor activity [29, 30]. This pattern of lipid abnormalities is very similar to that observed during the acute-phase response in a variety of acute and chronic diseases [31], and might be due to the release of proinflammatory cytokines [32]. It is possible that lipid abnormalities in cancer patients might represent an acute-phase response due to cytokines delivery by inflammatory cells around the tumor or by the tumor cell itself [33]. An experimental study showed that breast cancer cells consume cholesterol for the promotion and proliferation of breast cancer cells [34].

Although Adjuvant chemotherapy improves both disease-free and overall survival of breast cancer patients, accumulating evidence suggest that chemotherapy may cause significant alterations in the metabolic status of cancer survivors [35]. In our study, we have observed some significant metabolic changes during adjuvant chemotherapy of breast cancer patients such as increase in total cholesterol, triglycerides, LDL-C and Apo B, and decrease in HDL-C and Apo A1. Meanwhile, Apo A1 is the crucial component of HDL and both are protective factors of cardiovascular diseases [36]. Monika Sharma et al. investigate the longitudinal effect of chemotherapy on lipids in the same group of patients by monitoring the serum lipid profiles of 12 breast cancer patients throughout their multi-agent chemotherapy treatments have obtained the similar results of lipids changes before and after chemotherapy [37]. Some hypotheses implicate that chemotherapy may directly cause endothelial dysfunction, leading to cytokine alterations, and hence may cause development of lipids [38, 39]. Further evidence show that cancer-associated adipocytes modify the cancer cell phenotype leading to a more aggressive behavior [40]. An experimental study on mice with elevated circulating levels of 27 -hydroxycholesterol $(27 \mathrm{HC})$, a primary cholesterol metabolite, increased the metastasis of breast cancer cells to lung [34]. Furthermore, a research found that simvastatin, a highly lipophilic statin, was associated with reduced risk of breast cancer recurrence among Danish women [41]. Thus breast cancer patients taking statins could improve the quality of life and prognosis.

\section{Conclusions}

In summary, breast cancer patients have lower incidence of dyslipidemia compared to normal populations. However, the situation of dyslipidemia may become worsened after chemotherapy. Therefore, lipid monitoring and dyslipidemia prevention and treatment should be conducted for breast cancer patients at initial diagnosis and during chemotherapy.

\section{Abbreviations}

Apo A-1: Apolipoprotein A-1; Apo-B: Apolipoprotein B; HDL-C: High density lipoprotein-cholesterol; LDL-C: Low density lipoprotein-cholesterol; TC: Total cholesterol; TG: Triglyceride

Funding

This study was funded by National Natural Science Foundation of China (NSFC) (81372851).

\section{Availability of data and materials}

The datasets generated and analysed during the current study are available from the electronic medical records of Breast Cancer Center and Chongqing Physical Examination Center of the First Affiliated Hospital of Chongqing Medical University.

\section{Authors' contributions}

*These authors have contributed equally to this work, drafted sections of the manuscript and edited the entire paper. All authors read and approved the final manuscript.

Competing interests

The authors declare that they have no competing interests.

\section{Publisher's Note}

Springer Nature remains neutral with regard to jurisdictional claims in published maps and institutional affiliations.

Received: 10 January 2018 Accepted: 13 April 2018

Published online: 20 April 2018

References

1. Siegel RL, Miller KD, Jemal A. Cancer statistics, 2016. CA Cancer J Clin. 2016; 66(1):7-30. 
2. Berry DA, Cronin KA, Plevritis SK, et al. Effect of screening and adjuvant therapy on mortality from breast cancer. N Engl J Med. 2005;353(17):1784-92.

3. Huxley R, Lewington S, Clarke R. Cholesterol, coronary heart disease and stroke: a review of published evidence from observational studies and randomized controlled trials. Seminars Vascular Med. 2002;2(3):315-23.

4. Averina M, Nilssen O, Brenn T, Brox J, Arkhipovsky VL, Kalinin AG. Factors behind the increase in cardiovascular mortality in Russia: apolipoprotein Al and B distribution in the Arkhangelsk study 2000. Clin Chem. 2004;50(2): 346-54.

5. Pischon T, Girman CJ, Sacks FM, Rifai N, Stampfer MJ, Rimm EB. Non-highdensity lipoprotein cholesterol and apolipoprotein B in the prediction of coronary heart disease in men. Circulation. 2005;112(22):3375-83.

6. Fang L, Choi SH, Baek JS, et al. Control of angiogenesis by AIBP-mediated cholesterol efflux. Nature. 2013:498(7452):118-22.

7. Boyd NF, Guo H, Martin LJ, et al. Mammographic density and the risk and detection of breast cancer. N Engl J Med. 2007;356(3):227-36.

8. Boyd NF, Connelly P, Byng J, et al. Plasma lipids, lipoproteins, and mammographic densities. Cancer Epidemiol, Biomarkers Prev. 1995;4(7): 727-33.

9. Boyd NF, McGuire V. Evidence of association between plasma high-density lipoprotein cholesterol and risk factors for breast cancer. J Natl Cancer Inst. 1990;82(6):460-8.

10. Kitahara CM, Berrington de Gonzalez A, Freedman ND, et al. Total cholesterol and cancer risk in a large prospective study in Korea. J Clin Oncol. 2011;29(12):1592-8.

11. Kaye JA, Meier CR, Walker AM, Jick H. Statin use, hyperlipidaemia, and the risk of breast cancer. Br J Cancer. 2002;86(9):1436-9.

12. Eliassen AH, Colditz GA, Rosner B, Willett WC, Hankinson SE. Serum lipids, lipid-lowering drugs, and the risk of breast cancer. Arch Intern Med. 2005; 165(19):2264-71.

13. Kucharska-Newton AM, Rosamond WD, Mink PJ, Alberg AJ, Shahar E, Folsom AR. HDL-cholesterol and incidence of breast cancer in the ARIC cohort study. Ann Epidemiol. 2008;18(9):671-7.

14. Bicakli DH, Varol U, Degirmenci M, et al. Adjuvant chemotherapy may contribute to an increased risk for metabolic syndrome in patients with breast cancer. J Oncol Pharm Pract. 2016;22(1):46-53.

15. Yanling Shi XL, Ran L, Arshad B, Li H, Xu Z. Study on the status of thyroid function and thyroid nodules in chinese breast cancer patients. Oncotarget. 2017;8(46):80820-25.

16. Raymond Greene JFP, Rideout DF. Effect of D-Thyroxine on serum cholesterol. Br Med J. 1961;1(5239):1572-4

17. Huang J, Jin L, Ji G, et al. Implication from thyroid function decreasing during chemotherapy in breast cancer patients: chemosensitization role of triiodothyronine. BMC Cancer. 2013;13(1):334.

18. Cari M, ABdG K, Neal D, Freedman RH. Total cholesterol and Cancer risk in a large prospective study in Korea. J Clin Oncol. 2011;29(12):1592-8.

19. Iso H, Ikeda A, Inoue M, Sato S, Tsugane S, Group JS. Serum cholesterol levels in relation to the incidence of cancer: the JPHC study cohorts. Int J Cancer. 2009;125(11):2679-86

20. Ha M, Sung J, Song YM. Serum total cholesterol and the risk of breast cancer in postmenopausal Korean women. Cancer Causes Control. 2009; 20(7):1055-60.

21. Hiatt RA, Fireman BH. Serum cholesterol and the incidence of cancer in a large cohort. J Chron Dis. 1986;39(11):861-70.

22. Zhao Y, Wang H, Pan YY, Li N, Bian C. Association of lipid profile levels in premenopausal and postmenopausal women with breast cancer: a metaanalysis. Int J Clin Exp Med. 2016;9(2):552-63.

23. Moorman PG, Hulka BS, Hiatt RA. Association between high-density lipoprotein cholesterol and breast Cancer varies by menopausal status. Cancer Epidemiol Biomarkers Prev. 1998;7(6):483-88.

24. Kim Y, Park SK, Han W, et al. Serum high-density lipoprotein cholesterol and breast cancer risk by menopausal status, body mass index, and hormonal receptor in Korea. Cancer Epidemiol Biomarkers Prev. 2009;18(2):508-15.

25. Adana A, Llanos P, Makambi KH, Tucker CA. Cholesterol, lipoproteins, and breast cancer risk in African-American women. Ethn Dis. 2012;22(3):281-7.

26. Fiorenza AM, Branchi A, Sommariva D. Serum lipoprotein profile in patients with cancer, a comparison with non-cancer subjects. Int I Clin Lab Res. 2000;30(3):141-5.

27. Martyn L, Knapp SA-S, Riches PG. Alterations of serum lipids in breast Cancer effects of disease activity treatment and hormonal factor. Clin Chem. 1991;37(12):2093-101.
28. Kökoğlu E, Karaarslan I, Karaarslan HM, et al. Alterations of serum lipids and lipoproteins in breast cancer. Cancer Lett. 1994;82(2):175-8.

29. Vitols S, Björkholm M, Gahrton G, et al. Hypocholesterolaemia in malgnancy due to elevated low-density-lipoprotein-receptor activity in tumor cells: evidence from studies in patients with leukemia. Lancet. 1985;2(8465):1150-4.

30. Goldstein JL, Brown MS. The low-density lipoprotein pathway and itts relation to atherosclerosis. Annu Rev Biochem. 1977;46(1):897.

31. Veneracion G, Cabana JNS, Seymour M. Sabesin. Effects of the acute phase response on the concentration and density distribution of plasma lipids and apolipoprotein. J Lipid Res. 1989;30(1):39.

32. Hardardóttir I, Grünfeld C, Feingold KR. Effects of endotoxin and cytokines on lipid Metabolism. Curr Opin Lipidol. 1994;5(3):207-15.

33. Blackman JD, Cabana VG, Mazzone T. The acute-phase response and associated lipoprotein abnormalities accompanying lymphoma. J Internal Med. 1993;233(2):201.

34. Nelson ER, Wardell SE, Jasper JS, et al. 27-Hydroxycholesterol links hypercholesterolemia and breast cancer pathophysiology. Science. 2013; 342(6162):1094-8

35. de Haas EC, Oosting SF, Lefrandt JD, et al. The metabolic syndrome in cancer survivors. Lancet Oncol. 2010;11(2):193-203.

36. Ferre R, Aragones G, Plana N, et al. High-density lipoprotein cholesterol and apolipoprotein $\mathrm{A} 1$ levels strongly influence the reactivity of small peripheral arteries. Atherosclerosis. 2011;216(1):115-9.

37. Sharma M, Tuaine J, McLaren B, et al. Chemotherapy agents Alter plasma lipids in breast Cancer patients and show differential effects on lipid metabolism genes in liver cells. PLoS One. 2016;11(1):e0148049.

38. Vehmanen L, Saarto T, Blomqvist C, Taskinen MR, Elomaa I. Tamoxifen treatment reverses the adverse effects of chemotherapy-induced ovarian failure on serum lipids. Br J Cancer. 2004;91(3):476-81.

39. JA K. Reciprocal relationships between insulin resistance and endothelial dysfunction: molecular and pathophysiological mechanisms. Circulation. 2006;113(15):1888-904.

40. Dirat B, Bochet L, Dabek M, et al. Cancer-associated adipocytes exhibit an activated phenotype and contribute to breast cancer invasion. Cancer Res. 2011;71(7):2455-65.

41. Ahern TP, Pedersen L, Tarp M, et al. Statin prescriptions and breast cancer recurrence risk: a Danish nationwide prospective cohort study. J Natl Cancer Inst. 2011;103(19):1461-8.

\section{Ready to submit your research? Choose BMC and benefit from:}

- fast, convenient online submission

- thorough peer review by experienced researchers in your field

- rapid publication on acceptance

- support for research data, including large and complex data types

- gold Open Access which fosters wider collaboration and increased citations

- maximum visibility for your research: over $100 \mathrm{M}$ website views per year

At BMC, research is always in progress.

Learn more biomedcentral.com/submissions 